\title{
Gender Analysis Using the Empowerment Framework: Implications for Alleviating Women's Poverty in Nigeria
}

\author{
Dr. (Mrs.) Hussainatu Abdullahi
}

\author{
Department Of Economics, \\ Faculty Of Social Sciences, \\ Usmanu Danfodiyo University, Sokoto, Nigeria \\ E-mail:hussayabdul@yahoo.com \\ Dr. Yahya Zakari Abdullahi \\ Department Of Economics, \\ Faculty Of Social Sciences, \\ Usmanu Danfodiyo University, Sokoto, Nigeria \\ E-mail:ayzakari@yahoo.com
}

Doi:10.5901/ajis/2013.v2n1p123

\begin{abstract}
Poverty is a global problem of economic development affecting over a billion people worldwide. There has been growing inequality not only between rich and poor countries but also between men and women. Despite their crucial roles to the world economy, women constitute $80 \%$ of the world's poor group (Abdullahi' 200I). This brought about serious gender inequality which has become a crucial part of the development process and an important target of socio-economic policy. In Nigeria, there has been a proliferation of polices, programmes and projects that are derived from different macro-level economic and social policy approaches to third world development. So far these models have not guaranteed sustainable development and hence the quest for viable alternatives. This paper therefore, attempts to provide an alternative empowerment framework for poverty alleviation amongst women in Nigeria. Five different frameworks have been identified in the paper and the paper adopts the empowerment framework as the most viable. The paper concludes that if the empowerment framework can be used, it would go a long way in alleviating women's poverty in Nigeria. The paper further recommends that poor women must be allowed to define their own ends and means of development. They should therefore be allowed to participate in project formulation and implementation in order to have optimal results.
\end{abstract}

\section{Introduction}

Poverty is a global problem of economic development affecting over a billion people world wide. The current trend seems to be a widening inequality not only between the rich and poor countries, but also between men and women and this has posed great challenge for policy makers, especially in the Less Developed Countries (LDCs) particularly Nigeria. Today, in spite of Nigeria's rich endowment of human and material resources, about $70 \%$ of the population is estimated to live below the poverty line (Federal office of Statistics/World Bank, 1995). Poverty is not only a global phenomenon, but rather it is dominantly a problem of the present capitalist society in which a clear indication reveals a state of imperfection, contradictions and inequalities which every capital society must address (Abubakar, 2002). 
Globally, the issues of gender, class, racial, ethnic and religious inequalities have been heightened by capitalist structures and processes, consequently, disturbing a smooth process of development.

The feminization of poverty has become a very visible feature of this sad phenomenon (Glendning and Miller, 1992). Women constitute $80 \%$ of the world's poorest group in spite of their crucial roles in two spheres of life, that is, the reproductive economy (economy of care) and the productive economy (paid economy) (Abdullahi, 200I). Thus, gender inequality has become a crucial part of the development process and an important target of socio-economic policy (Afonja, 1996).

Very disheartening enough, there has been little or no consensus about the appropriate policy framework for promoting the general development of women and reducing or closing the gender gap and inequality, due principally to paucity of data and the low level of development theories about this area of social development (Abdullahi, I996). In the Less Developed Countries generally, and Nigeria in particular, there has been a proliferation of policies, programmes and projects that are derived from different macro-level economic and social policy approaches to Third World Development. So far these models have not guaranteed sustainable development, hence the quest for viable alternatives. The appropriate time to explore new strategies for poverty alleviation among the women folk is now, given the market increase in the level of public awareness and government commitment to gender programmes in the country. What we are searching for in our contemporary world is a clear understanding of development process, its essential dimensions, inputs and result oriented output for the society. It is useful to accept that gender issues are crucial to the development process, consequently, appropriate strategies for reducing or closing the gender gaps and inequality must be defined.

To facilitate our understanding of this write up, the paper is divided into four sections including this brief introduction. Section two discusses a review of the five frameworks of Women in Development (WID) adopted in the third World Countries, while section three highlights gender analysis using the empowerment framework for poverty alleviation amongst women in Nigeria. The last part concludes the paper with recommendations.

\section{A Review of the Five Frameworks of Women in Development (WID) Adopted in the Third World Countries and Their Limitations}

Having accepted the importance of gender issue to the development process, the next crucial step to take is a clear definition of the appropriate strategies for reducing or closing gender based gaps and inequality. The question that readily comes to mind, however, is how appropriate are the existing frameworks? How far have we achieved our goals and what new strategies must we embark upon?

In most Third World Countries, five different frameworks for Women in Development have been adopted. They include welfare equity, poverty, efficiency, equality and empowerment projects. On the other hand, the corresponding models of development include modernization policies of accelerated growth; basic needs approach, associated with redistribution, the structural adjustment policies which are compensatory in nature and the paradigm of sustainable human development. The attempt of each of this framework is to bridge the perceived gaps which exist in the development process so as to increase women's level of participation and benefits from development. According to Afonja (1996), each of this frameworks redefined women and gender concerns across a broad spectrum of sectors and differs from the other with respect to the way entrenched inequalities are transformed. We now review each of these frameworks briefly.

a. The Welfare Approach: This approach has been regarded as the most popular and oldest social policy adopted particularly for women in the third world countries. The approach predates Women in Development and was introduced by the colonial masters as a residual model of social welfare. As a result of their concern for a stable economic environment, and 
exploitation of resources, residual measures were provided for the most vulnerable groups (women) when social welfare was not given credence. The idea of social welfare came into existence only after the breakdown of the normal structure of supply, family and market. Thus, such residual measures were mostly emergency relief packages, especially to assist the low income women in support of their reproductive assignments.

The main criticisms leveled against this approach are that: Firstly, it has denied women access to international economic aid and prioritized government support for capital intensive, industrial and agricultural production in the formal sector. Secondly, it perceived women as passive recipients of development aids, thereby classifying them with the disabled and the sick. Thirdly, it placed too much emphasis on the reproductive roles of women rather than their lack of resources as the core problem. Finally, it is generally, not included among the integrative approaches and is believed to have marginalized women from the development process (Afonja, 1996).

b. The Equity Approach: As a result of the limitations posed by the welfare approach, the Equity approach was introduced during the United Nations' decade for women with the sole aim of achieving gender equity. While the approach is integrative in nature, it also recognized women's triple roles and placed a lot of emphasis on meeting the strategic gender needs through active state intervention, political and economic autonomy to women and a reduction in gender inequality. This was clearly spelt out during the International Women's Year Conference, where it was declared that 'the goal of the decade was integration of women into development processes. This essentially meant increase and an improvement of women's participation in the development process.

The limitations of this approach include: Firstly, equity has been difficult to achieve because it requires the backing of the political power and pressure on the part o the women themselves. Secondly, equity programmes lack base line information for planning, while the donor agencies are reluctant to change the existing culture values and traditions of the host countries. Thirdly, the equity approach is implicitly calling for the restructuring of power relations in the society, while government and donors explicitly support gender equality at the level of policy; integration only considers raising the number of women in existing policies and programmes.

c. The Anti-Poverty Approach: This approach has to do with the solution to the productive or practical needs of the women. This aim is pursued via small-scale income generation projects. According to this approach, reducing the income gap between men and women was perceived as the most crucial step towards reducing the level of poverty.

The main limitation of this approach include: Firstly, while the anti-poverty approach brought about proliferation of small-scale income generation activities among women, they were too small in scale to alleviate poverty. Secondly, such small-scale businesses were concentrated in the rural areas where they were shielded from loans and resources for larger scale businesses. Thirdly, the approach failed to consider those factors that will bring about project viability, easy access to raw materials, guaranteed markets and small scale production capacity. Finally, it created the problem of opportunity cost in respect of management of the business and the burden of domestic work and child care that were ignored.

d. The Efficiency Approach: This approach, which also seeks to provide solutions to the practical gender needs of women was influenced by macro-economic policies designed in response to the debt crisis and has advocated that, integrating women economically will guarantee a more efficient models for development. The main argument of this approach is that, if women's economic participation is enhanced and increased, it would guarantee equity. As a result of this notion, great efforts were geared towards understanding those salient 
constraints militating against women's economic participation and improving them as human resources for efficient and effective production.

This approach however, is saddled with the following shortcomings. Firstly, male bias in the definition of the household as performing a unified welfare function obscures the inequalities inherent in the efficiency approach. Secondly, reservations exist as to the fact that women's practical needs are at other costs to them, thus the approach has failed to account for women's strategic needs.

e. The Empowerment Approach: The empowerment approach is the most recent and popular approach which attempts to synthesize all the goals of earlier approaches in order to ensure a smooth transformation of the traditional social order, based on participatory doctrines. While this concept has been misunderstood, it is nevertheless less reactionary than the equity approach, and at the same time, it has outlined ways in which practical gender needs can be used to achieve strategic gender requirements. According to this approach, development is perceived to be more than increased access to resources and improved welfare level and as a process by which these benefits are obtained and sustained. The approach places serious emphasis on the participation by the target beneficiaries in the development process, rather than being passive recipients of the results of project outcomes.

Thus, this framework has a lot of advantages over the earlier ones. For instance: It encourages capacity acquisition on the part of the women which has a long run effect in improving their general socio-economic status. Secondly, the approach not only recognizes women's reproductive roles, it has improved on the dimensional definition of roles in the welfare mode by recognizing the triple roles of women. Thirdly, it capitalizes on the community management roles of women and through their organizations raises their consciousness to their subordinated conditions (Afshar, and Denise, 1992).

Arising from the above, therefore, the question arises as to how this empowerment framework can be used for alleviating women's poverty in Nigeria. It is to that we now.

\section{Gender Analysis Using the Empowerment Framework for Alleviating Women's Poverty in Nigeria}

Generally, poverty alleviation programme in Nigeria have been tailored along the welfare approach. The birth of the Structural Adjustment Programme in Nigeria saw the adoption of the Efficiency Approach which encouraged investments in Women's income generating activities, with emphasis on improving the productive capacities of women. However, due to the shortcomings of these approaches earlier noted above, attempts to integrate women into the development process could not be sustained. Consequently, policy makers were faced with greater challenges following the unfavourable economic environment which exacerbated the poverty situation of women in Nigeria. Thus, very little attention was paid to equity issues especially, under a situation where economic needs appear to be of paramount importance and in the face of very strong patriarchal institutions. While policy makers may be tempted to pursue income generation in order to provide more access to economic resources, this would satisfy just the short-term practical needs, while those intrinsic elements which would satisfy the strategic needs that can be sustained may be left untouched. Thus, in order to overcome this problem or limitation, it is useful to advance a more recent version of the empowerment framework which presents a holistic view of socio-economic development and gender equality.

Recent analysis of the empowerment framework saw the synthesization of all the earlier approaches which are represented in different stages of the process of achieving equality. The empowerment framework provides a way of understanding the process of women's advancement. In other words, Women's advancement could be understood in terms of a concern with five "levels of 
equity" and that empowerment is a necessary ingredient in the process of advancement towards equality, hence reducing the gender gap. These levels of equality are inter-connected and mutually reinforcing. These five levels are discussed, thus:

i. The Welfare Level: This is the level of the material welfare of females, relative to males. Gender gaps at this level could be described in terms of women being mere statistics rather than individuals capable of changing their destiny in life, i.e. they are mere passive recipients of welfare benefits. The gender gap at this level could be measured in terms of the disparity between males and females on indicators of nutritional status, mortality rates, literacy levels, educational qualifications, ownership of property etc.

However, any effort to solve this problem must involve women at all levels of decision-making concerning women's welfare. Thus, improved welfare can improve the capacity to act, consequently the basis for empowerment. This brings us to the next level i.e. ACCESS TO RESOURCES which is concerned with the first level of action to improve welfare.

ii. The Level of Access to Resources: Relative to men, women have less access to such resources as education, wage employment services and skills training which make productive employment possible. When compared to men, women even have less access to their own labour, i.e. women's labour is largely monopolized by men in the unpaid work of child rearing, domestic and subsistence labour that she does not even have enough time to invest in her own advancement.

Gender gaps in access to resources do not arise as a result of accident, but rather due to the discriminatory societal practices. Thus, overcoming gender gaps at this level will mean that women must act together collectively, and with men, to improve their access to resources.

This collective action to improve access to resources is the first important element of empowerment. The aim is to overcome the discriminatory practices, resistance by society and achieve equal opportunity irrespective of gender. In this case, there has to be a sense of purpose which should grow out of the process of conscientisation which brings us to the next level.

iii. The Level of Conscientisation: The gender gap which exists at this level is not material but rather a belief gap. The gap is between women believing that they cannot take action, that the man as the head of the household and should take all decisions, or that they can make action and that women and men can act together to change things for the better. In other words, it is the gap between women accepting their position as second class citizens or believing that they are equal citizens.

iv. \Conscientisation essentially involves the refusal to accept the world as you find it, and instead to resolve to change it. Though this is much easier to say than to achieve in practice, for instance, we were all brought up in a particular world and within the belief system of patriarchal ideology, which we were made to believe that the system of male control within the home is the natural order of life.

v. \Women's empowerment means sensitization to such beliefs and the rejection of such believes. It means recognizing the fact that women's subordination is not part of the natural order of things, but rather imposed by the discriminatory system that is socially built, but which can be dismantled. Conscientisation entails that the gender division of labour should not involve economic or political domination of one gender by the other. In this case, there has to be gender awareness which is essential in the empowerment process that provides the basis for mobilization on issues of women's inequality.

vi. Mobilization Participation Level: Conscientisation is a level of understanding which justifies collective action. It brings together the intellectual aspects of dissatisfaction, analysis and 
action. Mobilization is, thus, the practical aspect of conscientisation. Mobilization involves closing the gender gap in areas like political representation and decision making. The gender gap in public life results in men taking decisions and women being subjected to men's decisions. Women's increased mobilization at the grassroots level will be the basis for increased representation in public life and potential contribution towards increased empowerment. Mobilization for women's empowerment is the mobilization around gender issues. That is mobilization is not an end in itself, but is for the purpose of exerting more over the political system so that women's interests are served.

vii. Control Level: At the level of control the present gender gap is the unequal power relations between women and men. For instance, within the household, the husband exercise control over his wife's labour, time and income. The gender gap in control over income results in a gender gap between efforts and reward.

The wife makes the effort and the husband reaps the reward. Equality of control means a balance of power between women and men, so that neither is in a position of dominance. This means that women will have power alongside of men to decide their own destiny and that of their society, and to ensure that the interest of men and women are equally served. Women's increased participation in decision-making will lead to further empowerment when such participation is used to achieve increased control over the factors of production, to ensure women's equal access to resources and distribution of benefits. Such control and access to resources will enable improved welfare for themselves and their children.

The women's empowerment cycle could be shown as follows:

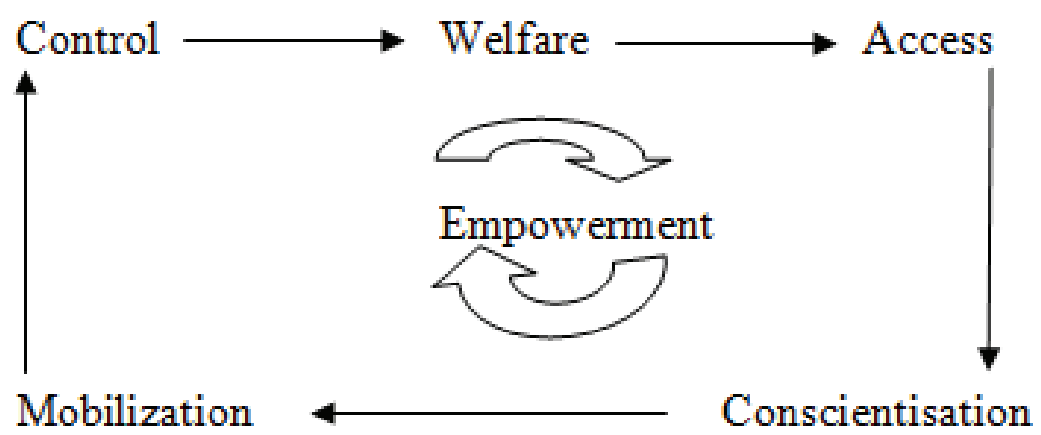

\section{Conclusion and Recommendation}

From the ongoing, it is clear that women the world over are faced with serious gender gaps. They constitute half of the world's population, and make important and largely unacknowledged contributions to economic life, and play crucial roles in all spheres of society, yet restrictive practices and constraints have not allowed women to take advantage of their numbers and position in order to improve their conditions of existence and decide their own destiny.

A new agenda for women the world over is not only crucial but ripe. It is time women take their destiny into their own hands and believe they can do it, and that they are equal to the men as citizens of the same world. Thus, the framework provided in this write-up could be used to develop sustainable projects for poor women in Nigeria. The framework is flexible and can be applied to any sector of 
development. While it is not possible to elaborate on the details for each development areas, due to space constraints, the five levels can easily be applied at the programme design stage and during project monitoring and evaluation, which forms the paradigm for sustainable human development. For optimal result, project formulation and implementation must be participatory. Poor women must be allowed to define their own ends and means of development. It is high time emphasis is shifted from merely helping women to create wealth to gaining access to equitable development/ this suggestion might appear unattainable, but there seems to be no other option than to manipulate the development process this way to the advantage of all concerned.

\section{References}

Abdullahi, H. (1996): "Analyzing Gender with a view to Closing or Reducing the Gender Gap", a paper presented at a one day seminar on GENDER DEVELOPMENT AND RELATED ISSUES, organized by the British Council Hall Kano/Kaduna in conjunction with Usmanu Danfodiyo University, Sokoto.

Abdullahi, H. (200I): "Poverty, Women and Economic Development in Nigeria. A proposal for Empowerment and Integration of Women's Economic Roles in the 2I $\mathrm{I}^{\text {st }}$ Century, a paper presented at the Faculty of Social Sciences and Administration 2001 Annual Conference,

Abdullahi, A. S. (2002): The Role of Economic System of Islam in Fostering a Viable International Economic Order", a Postgraduate Seminar paper presented to the Department of Economics, Faculty of Social Sciences, Usmanu Danfodiyo University, Sokoto.

Afonja, S. (1996): "Integrated Approaches to Women Development", in the proceeding of a one-day Seminar on Roles of Non-Governmental Organizations in Poverty Alleviation - Oyo State.

Afshar, H. (1989): "Gender Roles and the Moral Economy of Kin among Pakistani Women in Yorkshire”, New Community, I5 (2): 2 II -25.

Afshar, H. and Dennis, C. (eds.) (1992): Women and Adjustment Policies in the Third World, Macmillan, London.

Alcock, P. (1993): Understanding Poverty. The Macmillan Press Ltd., Hound Milk, Basingstocke, Hampshire, RG $212 \times 5$ and London

Arber, S. (1989): Gender and Class Inequalities in Health. Understanding the Differentials”, in J. Fox (eds.) Health Inequalities in European Countries, (Aldershot Gower).

Bakker, I. (eds.) (I99I): The Strategic Silence Gender and Economic Policy, Zed Books, London.

Baron, R. D. and Norris, G. M. (1976): "Sexual Divisions and the Dual Labour Market", in D. L. Barker and Allen S. (eds.) Dependence and Exploitation in Work and Marriage, (London Longman).

Beechey, V. (1987): Unequal Work, (London Version).

Beneria, L. and Feldmann, S. (eds.) (1992): Unequal Burden Economic Crisis, Persistent Poverty and Women's Work, West View Press.

Blackden, M. (1993): "Paradigm Postponed Gender and Economic Adjustment in Sub-Saharan African”, World Bank, Washington DC.

Boserup, E. (1986): Women's Role in Economic Development Aldershot Gower).

Callender, C. (1988): "Gender and Social Policy Women's Redundancy and Unemployment”, Unpublished Ph.D. Thesis, University of Wales.

Caragary, N.; Elson, D. and Grown, C. (eds.) (1995): "Gender, Adjustment and Macroeconomics" Special Issue of World Development, 23 (II).

Elson, D. (eds.) (2 ${ }^{\text {nd }}$ eds.) (1995): Male Bias in the Development Process, Manchester University Press.

Federal Office of Statistics and World Bank Publications

Glendining, C. and Miller, J. (eds.) (1992): Women and Poverty in Britain in the I990s, Harvest/Wheatsheaf.

Land, H. (1983): "Poverty and Gender: The Distribution of Resources within the Family", in M. Brown (eds.) The Structure of Disadvantage, London Heinemann). 
